BJMG 12/1 (2009) 61-64

$10.2478 / \mathrm{v} 10034-009-0002-\mathrm{z}$

SHORT COMMUNICATION

\title{
GORLIN'S SYNDROME: CASE REPORT AND MANAGEMENT PROTOCOL
}

\author{
Rosti $\mathrm{RO}^{1, *}$, Irem A ${ }^{2}$, Kayserili $\mathrm{H}^{1}$, Yalcın $\mathrm{S}^{2}$
}

*Corresponding Author: Rasim Ozgur Rosti, Department of Medical Genetics, Istanbul Medical Faculty, Istanbul University, 34390 Capa, Istanbul, Turkey; Tel./Fax: +90-212-534-84-40; E-mail: ozgurrosti@yahoo.com

\begin{abstract}
Gorlin's syndrome (GS) is a rare autosomal, dominant syndrome, characterized by multiple basal cell carcinomas, odontogenic keratocysts, a characteristic facial appearance, skeletal anomalies and malignancies of various organs throughout the body. We describe a 14-year-old girl with GS and propose a management protocol.

Key words: Basal cell carcinomas; Gorlin's syndrome (GS); Odontogenic keratocysts; Palmar/ plantar pits; PTCH1
\end{abstract}

\section{INTRODUCTION}

Gorlin's syndrome (GS, MIM \#109400) is an autosomal, dominantly inherited syndrome that shows high penetrance and variable expression. Its prevalence is estimated to be 1 in 40,000 [1]. First described by Gorlin and Goltz [2], the cardinal manifestations are multiple basal cell carcinomas, odontogenic keratocysts, palmar or plantar pits and ectopic calcifications [3]. The syndrome is caused by mutations in a tumor suppressor gene, PTCH1 (patched), which is located on 9q22.3. It encodes a trans membrane protein that represses transcription in specific cells of genes encoding members of the TGF- $\beta$ and Wnt families of signaling proteins [4].

1 Department of Medical Genetics, Istanbul Medical Faculty, Istanbul University, Istanbul, Turkey

2 Department of Oral Surgery, Faculty of Dentistry, Istanbul University, Istanbul, Turkey
Here we describe a 14 year-old girl with GS and propose a management protocol.

\section{CASE REPORT}

A 14-year-old Turkish female patient was referred to our clinics because of multiple odontogenic keratocysts revealed by panoramic X-ray at the School of Dentistry, Istanbul, Turkey. She was the second child born to a consanguineous couple. Following an uneventful pregnancy, she was born via spontaneous vaginal delivery. No problems were encountered during the postnatal adaptation period and her psychosocial motor development was normal. She had a whole set of deciduous teeth replaced by an extra whole set of deciduous teeth between the ages of seven and 10. After 10 years of age, her permanent teeth began to erupt and were noted to be 'structurally imperfect and some on top of the others' by the mother. She developed an abscess in the left maxillary region at the age of 11. Dental examination revealed multiple odontogenic cysts. Cyst enucleation was performed and orthodontic treatment was initiated.

Physical examination at the age of 14 revealed macrocephaly $(59.5 \mathrm{~cm},>97$ centile) with frontal bossing, telecanthus, broad nasal root, tubular nose, high-arched palate and mild prognathism. Ten palmar pits were observed on the left and four on the right hand (Figure 1). One plantar pit was found on the left foot. Multiple basal cell nevi were located on the periorbital region, neck, pectoral region and on the back (Figure 2). Systemic examination was 


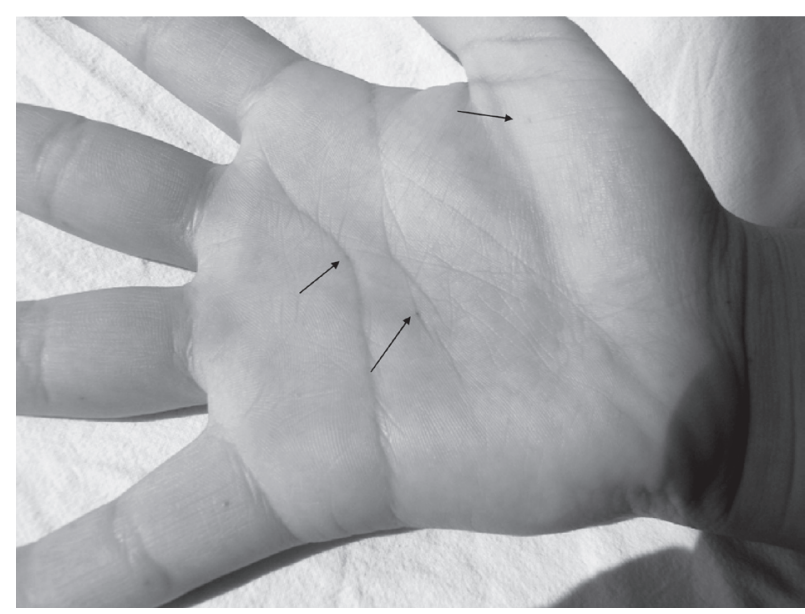

Figure 1. Note the palmar pits on the right hand (shown by the black arrows).

unremarkable. The presence of multiple basal cell nevi, odontogenic keratocysts, palmar pits and a characteristic facies, three major and one minor criteria, led to the diagnosis of GS.

Neither her parents nor her brother showed any clinical manifestations of the disease. Renal ultrasonography showed normal results. No structural abnormalities were reported in ophtalmology consultation. The nevi were excised and the histopathology report was compatible with early stage basal cell carcinoma.

\section{PROPOSED MANAGEMENT PROTOCOL}

The diagnostic criteria for GS and frequencies of the major findings are reported in Table 1 [5]. The presence of multiple basal cell nevi, odontogenic keratocysts, palmar/ plantar cysts and a characteristic facial appearance fulfill the criteria for the diagnosis in our patient.

The follow-up of patients with GS is important because proper patient care leads to early diagnosis and treatment of neoplasms of multiple tissues, thereby improving the quality of life of patients. We here propose a management protocol as outlined in Table 2.

Skin findings should be monitored closely at 6-monthly intervals, especially after puberty, since the rate of malignant transformation increases with full-blown puberty [1]. Since sunlight is a promoter of such malignancies, sun screen precautions should

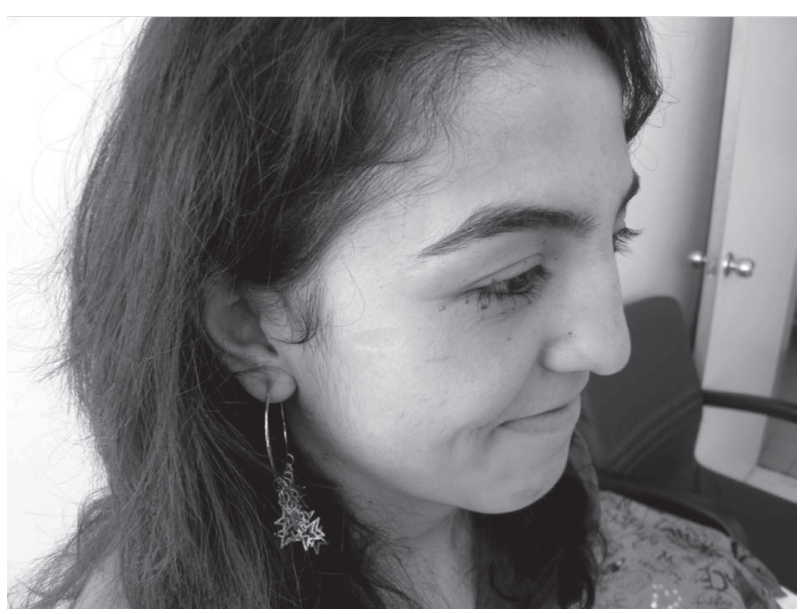

Figure 2. Note the basal cell nevi in the periorbital region.

be strongly recommended [6].

Odontogenic keratocysts may appear as early as the fifth year of life [7]. We recommend that annual dental screening should start at the age of 8 years. If there is a jaw cyst then the frequency of dental visits should be adjusted accordingly.

Surveillance of neoplasms, other than skin neoplasms, is crucial for the survival of the patient. Medulloblastoma typically presents during the first 2 years of life as opposed to 7 to 8 years in the general population, and the likelihood of developing a medulloblastoma is unlikely after 7 years of age [5]. Due to the fact that craniospinal irradiation results in hundreds of basal cell carcinomas of the irradiated field, routine scanning with computed tomography or excessive use of radiography is not recommended [8]. There is no evidence that magnetic resonance imaging is of value. Clinical neurological examination at 6-month intervals is the choice of surveillance until 3 years of age, when the clinical evaluation could be rescheduled to once a year. In older children, headaches, vomiting, dizziness, or a change in personality or habits reported by the parents, could be pivotal hints for detection of central nervous system neoplasms.

The musculoskeletal manifestations consisting of bifid, fused or splayed ribs; missings ribs or vertebrae; lack of segmentation of cervical or upper thoracic vertebrae, ectopic calcification of various sites and pseudocystic lytic bone lesions, should only be documented if the diagnosis is uncertain, since radiation exposure promotes the occurrence of skin malignancies $[5,8]$. 
Table 1. Diagnostic criteria list and the frequencies of major findings [5]

\section{Diagnostic Criteria for Gorlin's Syndrome}

\section{Major Criteria:}

1) Multiple $(>2)$ basal cell carcinomas or one under the age of 30 years or $>10$ basal cell nevi $(90 \%)$

2) Odontogenic keratocyst (proven on histology) (65\%) or polyostotic bone cyst (30\%)

3) Palmar or plantar pits (three or more) $(65-80 \%)$

4) Ectopic calcification: Lamellar or early ( $<20$ years) falx calcification $(55-95 \%)$

5) First-degree relative affected

\section{Minor Criteria:}

1) Congenital skeletal anomaly: bifid, fused, splayed or missing rib or fused vertebrae

2) Occipito-frontal circumference $>97$ centile with bossing

3) Cardiac or ovarian fibroma

4) Medulloblastoma (primitive neuroectodermal tumor)

5) Lymphomesenteric or pleural cysts

6) Congenital malformation: cleft lip and/or palate, polydactyly, eye anomaly (cataract, cloboma, microphthalmia)

A diagnosis can be made when two major OR one major and two minor criteria are fulfilled

Table 2. Proposed management protocol for Gorlin's syndrome

\begin{tabular}{|l|l|l|}
\hline Consultations/Investigations & Initial Work-Up & Long-Term Follow-Up \\
\hline Dermatological consultations & should be performed & 6-month intervals \\
\hline Dental examinations & should be performed & annually after 8 years of age \\
\hline Neurological examinations & should be performed & $\begin{array}{l}\text { at 6-month intervals until age 3, } \\
\text { annually thereafter }\end{array}$ \\
\hline Ophthalmological examinations & should be performed & $\begin{array}{l}\text { should be scheduled by } \\
\text { ophthalmologists }\end{array}$ \\
\hline $\begin{array}{l}\text { Cardiology consultations } \\
\text { (echocardiogram) }\end{array}$ & optional (unless symptoms exist) & optional (unless symptoms exist) \\
\hline Renal utrasonography & optional (unless symptoms exist) & optional (unless symptoms exist) \\
\hline
\end{tabular}

Cardiac fibromas and ovarian fibromas occur at a higher frequency in GS than expected [5]. Since cardiac fibromas, likely to cause clinical problems, may be present from very early in raphy is optional unless there are suggestive symptoms. The same approach applies to the possibility of chylous or lymphatic cysts of the mesentry [1].
The ocular problems encountered in GS include congenital cataract(s), microphthalmia, orbital cysts, coloboma of the iris, choroid and optic nerve, strabismus and nystagmus [3]. An ophthalmologic examination at the time of diagnosis is recommended. Regular ophthalmologic examinations are recommended if there is an abnormality that necessitates 
follow-up. In summary, we highly recommend the advised follow-up protocol of GS for better management of complications, and for early detection of tumors that may necessitate early intervention.

\section{REFERENCES}

1. Cassidy SB, Allanson JE. Management of Genetic Syndromes. Hoboken, NJ: John Wiley\& Sons, 2005.

2. Gorlin RJ, Goltz RW. Multiple nevoid basal-cell epithelioma, jaw cysts and bifid rib. A syndrome. N Engl J Med 1960; 262:908-912.

3. Evans DGR, LadusansEJ, Rimmer S, Burnell LD, Thakker N, FarndonPA. Complications of the naevoid basal cell carcinoma syndrome: results of a population based study. J Med Genet 1993; 30(6): 460-464.

4. Hahn H, Wicking C, Zaphiropoulos PG, Gailani MR, Shanley S, Chidambaram A, Vorechovsky
I, Holmberg E, Unden AB, Gillies S, Negus K, Smyth I, Pressman C, Leffell DJ, Gerrard B, Goldstein AM, Dean M, Toftgard R, Chenevix-Trench G, Wainwright B, Bale AE. Mutations of the human homolog of Drosophilia patch in the nevoid basal cell carcinoma syndrome. Cell 1996; 85(6): 841-851.

5.Gorlin RJ.Nevoidbasalcellcarcinoma(Gorlin) syndrome. Genet Med 2004; 6(6): 530-539.

6.Goldstein AM, Bale SJ, Peck GL, DiGiovanna JJ. Sun exposure and basal cell carcinomas in basal nevus syndrome. J Am Acad Dermatol 1993; 29(1): 34-41.

7. Dowling PA, Fleming P, Saunders IDF, Napier SS. Odontogenic keratocysts in a 5-year-old: initial manifestations of nevoid basal cell carcinoma syndrome. Pediatr Dent 2000; 22(1): 53-55.

8. O'Malley S, Weitman D, Olding M, Sekhar L. Multiple neoplasms following craniospinal irradiation of medulloblastoma in a patient with nevoid basal cell carcinoma syndrome. J Neurosurg 1997; 86(2): 284-288. 